\title{
Antibacterial properties and phytochemical screening of Tamarix nilotica leaves from Sudan
}

\author{
Eiman Mohammed Ali Mustafa ${ }^{1}{ }^{*}$, Hatil Hashim EL-Kamali ${ }^{1}$, Salah Ahmed Ali ${ }^{2}$, Mohammed Yagoub AL- \\ Amir 3, Marwa EHag Mohammed 1, Safa Omer Barakat 1, Safia Mohammed Shareef ${ }^{1}$ \\ ${ }^{1}$ Department of Botany, Faculty of Science and Technology, Omdurman Islamic University, Sudan. \\ 2 Department of Biotechnology, Faculty of Science and Technology, Omdurman Islamic University, Sudan. \\ ${ }^{3}$ Department of Microbiology, Faculty of Medical Laboratories, Omdurman Islamic University, Sudan.
}

Publication history: Received on 07 April 2018; revised on 21 April 2018; accepted on 04 May 2018

https://doi.org/10.30574/gscbps.2018.3.2.0028

\begin{abstract}
The antibacterial activity of crude extracts of leaves coated with wax and other de-waxed leaves of Tamarix nilotica, against nine human pathogenic bacteria were evaluated using the agar plate well-diffusion method with plant extract concentration of $100 \mathrm{mg} / \mathrm{ml}$. The minimum inhibitory concentration (MIC) was determined. The antibacterial activity was found in the least MIC, as $7.5 \mathrm{mg} / \mathrm{ml}$, belonged to Staphylococcus aureus and Pseudomonas aeruginosa. Most susceptible gram-negative bacteria were $P$. aeruginosa and least susceptible gram-negative bacteria were $E$. coli and $S$. typha. In gram-positive bacteria, most and least susceptible were $S$. aureus and $B$. cereus, respectively. These findings should stimulate the research for novel, natural product such as many anti-bacterial agents. The percentage yield of epicuticle wax from Tamarix nilotica leaves, extracted with n-hexane was $0.7 \%$. The results of the preliminary phytochemical analyses of the ethanol extract of the leaves coated with wax and de-waxed leaves of Tamarix nilotica were performed. Steroids, phenolic compounds, saponins, tannins, flavonoids and sugars are present in all of the two samples analyzed except sugars in de-waxed leaves.
\end{abstract}

Keywords: Antibacterial; Phytochemical; Tamarix nilotica; Wax and de-waxed leaves

\section{Introduction}

Tamarix nilotica is a member of the family Tamaricaceae. It is a shrub that Tamaricaceae is relatively a small family of 4 genera and 120 species [1]. Tamarix nilotica reported to contain active compounds with different biological activities based on their use in traditional medicine [2]. Chemical study of the aerial parts of T. nilotica from Saudi Arabia led to the isolation of pentacyclic triterpenoid, 3-0-trans-caffeoylisomyricadiol, in addition to nine known compounds. In radical scavenging (DPPH) assay, 3-0-trans-caffeoylisomyricadiol exhibited potent antioxidant activity with an $\mathrm{IC}_{50}$ value of $3.56 \mu \mathrm{M}$, while that for quercetin (standard antioxidant) was $5.72 \mu \mathrm{M}$ [3]. Nilocitin (2, 3-digalloyl-Dglucopyranose), methyl gallate 4-methyl ether [4]. A number of $\mathrm{N}$-methylproline analogues have been found to accumulate in different species of Tamarix. These include N-methyl-L-proline (MP), trans-4-hydroxy-N-methyl-Lproline (M4HP) and trans-3-hydroxy-N-methyl-L-proline (M3HP) [5]. Medicinal plants represent a rich source of antimicrobial agents [6]. Medicinal plants have been used, from the ancient time, to prevent and treat various health problems. Plants are still an independent source of medication in the contemporary health care delivery system. Their role is twofold in the development of medicines and served as a natural blue print for the development of new drugs [7].

\footnotetext{
${ }^{*}$ Corresponding author

E-mail address: eimanlife7@ gmail.com
}

Copyright (C) 2018 Author(s) retain the copyright of this article. This article is published under the terms of the Creative Commons Attribution Liscense 4.0. 
Focus on plant research has increased all over the world and large body of evidence has collected to show immense potential of medicinal plants used for their therapeutic abilities against microbe. New trend of research concentrating on preparing plant extracts has been established for producing medicinal drugs based on scientific criteria. Besides, these extracts overcome the harmful effect encountered with the use of antibiotics and the resistance of microbes to the antibiotics.

This resistance encouraged researchers to practice alternatives from plant sources with low cost to counteract microbial infections. The mechanisms by which plant extracts control bacterial take many routes. It has been proved that various plants extracts possess bacteriostatic and bacteriocidal effects and most of these plants contain many active compounds. Consequently, they are multipurpose drugs at the same time.

The main objectives of this work are to test crude extracts of leaves coated with wax and de-waxed leaves of Tamarix nilotica for their antibacterial activity against nine human pathogenic bacteria. To determine the effectiveness of plant extracts against bacteria screened those with higher propensity for Gram-positive bacteria or Gram-negative bacteria or that equal or nearly equal effectiveness for both types of bacteria. Nine bacterial strains have been chosen for this study. Staphylococcus aureus, Bacillus cereus, Pseudomonas aeruginosa, Escherichia coli, Klebsiella pneumonia, Proteus mirabilis, Salmonella typhi, Salmonella para typhi A and Shigella dysentriae. Tocarry out phytochemical screening for plant studied.

\section{Material and methods}

\subsection{Plant material}

Leaves of Tamarix nilotica were collected from a flowering tree in Omdurman Islamic University Campus during the winter time 2009. Taxonomic authentication of the plant was carried out by one author, Prof. HH EL-Kamali.

\subsection{Wax Extraction}

Epicuticular wax was extracted by immersing the plant sample in n-hexane for 90 sec. This procedure extracts only surface hexane - soluble compounds without disturbing the leaf interior [8]. N-hexane extract was filtered and concentrated by evaporation. Total $0.7 \mathrm{~g}$ wax was obtained after evaporating the $\mathrm{n}$-hexane.

\subsection{Bacteriological Techniques [9]}

\subsubsection{Cup plate Method (Inhibition Zone) for antibacterial testing}

Using a flamed and then cooled $8 \mathrm{~mm}$ cork-borer, 3 cups were cut out of each of the inoculated agar plates with the test organisms. The cut discs of agar were removed and discarded in disinfected container. By means of standard pipettes, $0.1 \mathrm{ml}$ aliquots of each of the two different extracts were added to the appropriate cuts. The third cup was used for dimethyl sulfoxide (DMSO) as control. An average of three cups was used for each solution against each test organisms. After filling the reservoirs with the appropriate solutions, the plates were incubated in the upright position at $37^{\circ} \mathrm{C}$ for 18-20 hrs. The plates were checked for bacterial growth after the incubation period of the resultant zones of growth inhibition were accurately measured in $\mathrm{mm}$.

\subsubsection{Minimum Inhibitory Concentration (MIC) for antibacterial testing}

A set of 7 sterile test tubes each containing $5 \mathrm{ml}$ of double strength broth, were placed in a rack and numbered 1-7.Using a graduated pipette appropriate volumes of extract solution were added to each tube and mixed thoroughly with the double-strength broth. This mixing had been done before the organisms were added, so that they don't come into contact with the undiluted solution. Sufficient sterile distilled water has been added to each tube to wake the volume up to $9.8 \mathrm{ml}$ and mixed thoroughly before the addition of organism.

$0.2 \mathrm{ml}$ of a diluted suspension at the test organism was added to each tube. The suspension of organism has been prepared by 1 in 1000 dilution of an 18-24 hrs broth culture. Finally, we have had a total of $10 \mathrm{ml}$ in each tube and the concentration of extract was calculated in each tube. The tubes were then incubated at $37{ }^{\circ} \mathrm{C}$ for 48 hrs. After the incubation period the tubes checked and examined for growth. 


\subsection{Preliminary phytochemical analysis}

A $10 \mathrm{~g}$ of the powdered sample was extracted with ethanol by cold extraction. The two samples extracts were tested for the steroids, phenolic compounds, saponins, tannins, flavonoids and sugars. The phytochemical tests were performed according to the method of Brinda [10] and are presented in Table 1.

Table 1 Preliminary phytochemical screening

\begin{tabular}{lll}
\hline $\begin{array}{c}\text { Test for detection of } \\
\text { secondary metabolites }\end{array}$ & Protocol & Observation \\
\hline Steroids & $\begin{array}{l}\text { Test solution }+ \text { a few drops of chloroform }+3 \text { drops of } \\
\text { acetic anhydride and one drop of sulphuric acid }\end{array}$ & $\begin{array}{l}\text { Purple color changing to } \\
\text { blue or green }\end{array}$ \\
Phenolic compounds & Test solution in alcohol + 1 drop of neutral ferric chloride & Intense color \\
Saponins & Test solution + water and shake & Foamy lather \\
Tannins & Test solution + water + lead acetate & White precipitate \\
Flavonoids & Test solution in alcohol + a bit of magnesium and one or & Red or orange red color \\
& two drops of concentrated hydrochloric acid and heat & Green to purple color \\
Sugars & Test solution + very small quantity of Anthrone reagent + \\
\end{tabular}

\section{Results and discussion}

The antibacterial properties of the ethanolic extracts of Tamarix nilotica leaves coated with wax (normal) and also leaves de-waxed (treated with n-hexane) at concentration $100 \mathrm{mg} / \mathrm{ml}$ were tested against nine locally isolated bacteria. The inhibition zones diameter results are presented in Table 2.

The Tamarix nilotica plant leaves extracts inhibited growth of pathogenic bacteria tested in both extracts including Staphylococcus aureus, Bacillus cereus, Pseudomonas aeruginosa, Escherishia coli, Klebsiella pneumonia, Proteus mirabilis, Salmonella typhi, Salmonella para typhi A, and Shigella dysentriae. The obtained results revealed that, among the investigated efficiency Tamarix nilotica extracts, the best antibacterial activity was obtained by the extract of dewaxed extract. The highest antibacterial activity values ranged $18-16 \mathrm{~mm}$ ). Whereas, lowest antibacterial activity were (13 and $15 \mathrm{~mm}$ ) noticed in extract of leaves coated with wax. The results obtained similar with the results of Amani [11].

Ethanol extract of leaves coated with wax was found effective against all tested bacteria except $E$. coli, whereas, ethanol extract of de-waxed leaves was exhibited intermediate activity against all tested bacteria (16-18 mm).

Table 2 The inhibition zones diameters ( $\mathrm{mm}$ ) of tested bacterial pathogens

\begin{tabular}{lccc}
\hline Bacteria & \multicolumn{2}{c}{ Diameter of zone of inhibition (mm) (Activity Index) } \\
& Leaves coated with wax & De-waxed leaves & Gentamicin (10 $\mathbf{\mu g})$ \\
\hline Staphylococcus aureus & $15(0.6)$ & $18(0.75)$ & 24 \\
Bacillus cereus & $16(0.9)$ & $17(1.0)$ & 17 \\
Pseudomonas aeruginosa & $15(1.0)$ & $16(1.06)$ & 15 \\
Escherishia coli & $13(0.7)$ & $16(0.8)$ & 20 \\
Klebsiella pneumonia & $15(0.9)$ & $16(0.9)$ & 17 \\
Proteus mirabilis & $15(0.7)$ & $18(0.9)$ & 21 \\
Salmonella typhi & $16(0.8)$ & $17(0.9)$ & 20 \\
Salmonella para typhi A & $17(0.9)$ & $17(0.9)$ & 19 \\
Shigella dysentriae & $15(0.9)$ & $17(1.0)$ & 17 \\
\hline
\end{tabular}

No inhibition shown by using DMSO in the negative control

Activity Index = Inhibition zone diameter of extract/inhibition zone diameter of antibiotic 
The Minimum Inhibitory Concentrations (MICs) values of de-waxed extract against tested bacteria are summarized in Table 3.

Table 3 The MIC of de-waxed leaves extract against tested microorganisms

\begin{tabular}{lll}
\hline Bacteria & $\begin{array}{l}\text { Gentamicin } \\
(\boldsymbol{\mu g} / \mathbf{m l})\end{array}$ & MIC (mg/ml) \\
\hline Staphylococcus aureus & $>10$ & 7.5 \\
Bacillus cereus & $<10$ & 10 \\
Escherichia coli & $<10$ & 10 \\
Pseudomonas aeruginosa & $>5$ & 7.5 \\
Salmonella typhi & 4.0 & 10 \\
\hline
\end{tabular}

The percentage yield of epicuticular wax from Tamarix nilotica leaves, extracted with n-hexane was $0.7 \%$. The results of the preliminary phytochemical analysis of the ethanol extract of the leaves coated with wax and de-waxed of Tamarix nilotica are presented in Table 4. Steroids, phenolic compounds, saponins, tannins, flavonoids and sugar present in all the two samples analyzed except sugars in de-waxed leaves. The ethanolic extract of the plants revealed the presence of tannins and flavonoids with moderate amount in Tamarix nilotica leaves coated with wax. Likewise, found with low amount in leaves coated de-wax. Steroids and saponins were found moderate amount in de-waxed leaves and low amount in leaves coated with wax. Whereas, the phenolic compound present with high amount. On the other hand, alkaloids were absence in leaves coated with waxand de-waxed leaves of Tamarix nilotica. Sugar was present with low amount in leaves coated with wax, while, it was absence in de-waxed leaves (Table 4).

Table 4 Preliminary phytochemical screening of Tamarix nilotica

\begin{tabular}{lcc}
\hline \multicolumn{1}{c}{ Phytochemicals } & Leaves coated with wax & De-waxed leaves \\
\hline Steroids & + & ++ \\
Phenolic compounds & +++ & + \\
Saponins & + & ++ \\
Tannins & ++ & + \\
Flavonoids & ++ & + \\
Sugar & + & - \\
\hline
\end{tabular}

\section{Conclusion}

Utilization of Tamarix nilotica extracts ethanolic of de-waxed leaves as antibacterial was most effective in inhibiting bacteria studied diameters zones varied from 13 to $18 \mathrm{~mm}$ at lowest MIC concentration between $7.5 \mathrm{and} 10 \mathrm{mg} / \mathrm{ml}$. The plant leaves analysis revealed the presence of different bioactive compounds including tannins, flavonoids, phenolic compounds, the antibacterial activities may attributed to these compounds.

\section{Compliance with ethical standards}

\section{Acknowledgments}

The authors would like to thanks department of Botany, Faculty of Science and Technology, and Faculty of Medical Laboratories, Omdurman Islamic University, Sudan.

\section{Disclosure of conflict of interest}

Eiman Mohammed Ali Mustafa, Hatil Hashim EL-Kamali , Salah Ahmed Ali , Mohammed Yagoub AL-Amir , Marwa EHag Mohammed, Safa Omer Barakat, Safia Mohammed Shareef declare that they have no conflict of interest. 


\section{References}

[1] Trease GE and Evans C. (2002). Pharmacognosy, WB Saunders Company Ltd, London, 15 th ed., pp. 30.

[2] Al-Kahtani JSM, Al-Yahya MA and Al-Meshal IA. (2000). Medicinal plants of Saudi Arabia, King Fahad National Library Cataloging, Riyadh, Kingdom of Saudi Arabia, vol. 2, pp. 62.

[3] Orfali RS, Ebada SS, EL-Shaae AM, AL-Taweel AM, Lin WH, Wray V and Proksch P. (2009). 3-0- transcaffeoylisomyricadiol: a new triterpenoid from Tamarix nilotica growing in Saudi Arabia. Zeitschrift fur Naturforschung C, 64(9/10), 637-643.

[4] Nawwar MAM, Souleman AMA, Buddrus J and Linscheid M. (1984). Flavonoids of the flowers of Tamarix nilotica. Phytochemistry, 23, 2347-2349.

[5] Jones GP, Naidu BP, Waisel Y, Solomon A and Leslie G. (2006). Occurrence and stress response of N-methylproline compounds in Tamarix species. Phytochemistry, 67(2), 156-160.

[6] Awaad AS, Soliman G A, El-Sayed DF, El-Gindi OD and Alqasoumi SI. (2012). Hepatoprotective activity of Cyperus alternifolius on carbon tetrachloride-induced hepatotoxicity in rats. Pharmaceutical Biology, 50(2), 155161.

[7] Asres K, Taddese S and Gebremariam T. (2003). In vitro antimicrobial activities of some selected topically applied medicinal plants of Ethiopia. Ethiopian Pharmaceutical Journal, 21, 34-45.

[8] Medina E, Aguiar G, Gomez M, Aranda J, Medina D and Winter K. (2006). Taxonomic significance of the epicuticular wax composition in species of the genus Clusia from Panama. Biochemical systematic and Ecology, 34, 319-326.

[9] Colee JG, Duguid JP, Fraser AG and Marmion BP. (1989). Laboratory control of antimicrobial therapy. In Mackie \& Mc. Cartney: Practical Medical Microbiology, Longman Group, UK, 161-181.

[10] Brinda P, Sasikala B, Purushothaman K. (1981). Pharmacognostic studies on Merugan kizhangu, Bulletin of Medico-Ethnobotanical Research, 3(1), 84-96.

[11] Amani SA, Mohamed EZ, Monerah RA and Sahar KA. (2014). Phytochemical analysis and antimicrobial activity of medicinal plants against pathogenic microorganisms. Life Science Journal, 11(7), 350-354.

\section{How to cite this article}

Mustafa, EMA, El-Kamali HH, Ali SA, AL-Amir MY, Mohammed ME, Barakat SO and Shareef SM. (2018). Antibacterial properties and phytochemical screening of Tamarix nilotica leaves from Sudan. GSC Biological and Pharmaceutical Sciences, 3(2), 06-10. 